\title{
Glutathione as an endogenous sulphur source in the yeast Saccharomyces cerevisiae
}

\author{
Marc T. Elskens, Charles J. Jaspers and Michel J. Penninckx* \\ Laboratoire de Microbiologie de l'Université libre de Bruxelles, Unité de Physiologie et Ecologie Microbienne, \\ Institut de Recherches du CERIA, 1 Av. E. Gryson, B-1070, Bruxelles, Belgium
}

(Received 10 July 1990; revised 25 September 1990 ; accepted 14 November 1990)

\begin{abstract}
Glutathione-deficient mutants (gshA) of the yeast Saccharomyces cerevisiae, impaired in the first step of glutathione (GSH) biosynthesis were studied with respect to the regulation of enzymes involved in GSH catabolism and cysteine biosynthesis. Striking differences were observed in the content of the sulphur amino acids when gsh $A$ mutants were compared to wild-type strains growing on the same minimal medium. Furthermore, all mutants examined showed a derepression of $\gamma$-glutamyltranspeptidase $(\gamma$-GT), the enzyme initiating GSH degradation. However, $\gamma$-cystathionase and cysteine synthase were unaffected by the GSH deficiency as long as the nutrient sulphate source was not exhausted. The results suggest that the mutants are probably not impaired in the sulphate assimilation pathway, but that the $\gamma$-glutamyl cycle could play a leading role in the regulation of the sulphur fluxes. Studies of enzyme regulation showed that the derepression of $\gamma$-GT observed in the gsh $A$ strains was most probably due to an alteration of the thiol status. The effectors governing the biosynthesis of cysteine synthase and $\gamma$ cystathionase seemed different from those playing a role in $\gamma$-GT regulation and it was only under conditions of total sulphate deprivation that all these enzymes were derepressed. As a consequence the endogenous pool of GSH was used in the synthesis of cysteine. GSH might, therefore, fulfil the role of a storage compound.
\end{abstract}

\section{Introduction}

The thiol tripeptide glutathione (GSH) accounts for about $1 \%$ of the dry weight of the yeast Saccharomyces cerevisiae and plays a leading part in the detoxification of endogenous oxoaldehydes (Penninckx et al., 1983) and the regulation mechanisms of drug bioreduction (Elskens et al., 1988) in this organism. A role for GSH in sulphur metabolism was apparently not previously envisaged in studies of yeast metabolism (Jones \& Fink, 1982; Ono et al., 1988). GSH was, however, cited as a growth factor for micro-organisms (see Penninckx \& Jaspers, 1982). It also appears to be an alternative source of sulphur for morphogenesis of Bacillus cereus spores (Cheng et al., 1973) and vegetative cells of a species of cyanobacterium (Giddings et al., 1981). Observations by several investigators (see Rennenberg, 1982) are consistent with the idea that GSH functions as a storage form of reduced sulphur in plants; this function has also been proposed

\footnotetext{
Abbreviations: BSO, buthionine-( $S, R)$-sulphoximine; mBRB, monobromobimane; GSH, glutathione; GSSG, oxidized glutathione; $\gamma-\mathrm{GT}$, $\gamma$-glutamyltranspeptidase.
}

for animal cells (Kosower \& Kosower, 1978; Reed et al., 1983).

Several lines of evidence indicate that GSH metabolism proceeds in many eukaryotic cells via the $\gamma$-glutamyl cycle (Meister, 1983). In S. cerevisiae, however, GSH catabolism appears to be mediated by $\gamma$-glutamyltranspeptidase $(\gamma-\mathrm{GT})$ and cysteinylglycine dipeptidase only, and leads to the formation of glutamate and $\gamma$-glutamyl amino acids (Jaspers et al., 1985). The physiological role of yeast transpeptidation reactions is not well understood. $\gamma$-GT and GSH were initially thought to be involved in the bulk absorption of amino acids by $S$. cerevisiae, but these claims have been contradicted (Robins \& Davies, 1981; Jaspers \& Penninckx, 1981; Payne \& Payne, 1984). In the course of an investigation into the biochemical characterization of GSH-deficient yeast mutants, we observed that these mutants showed a derepression of $\gamma$-GT. Efforts were made to understand the physiological significance of this regulation pattern by using mutants impaired in the first step of GSH biosynthesis. It was of interest to know if the regulation of other sulphur-related enzymes was also altered in these strains. In this paper, we present evidence that GSH might serve as an endogenous sulphur reservoir when $S$. 
cerevisiae cells are deprived of any external sulphur nutrient. If the $\gamma$-glutamyl cycle does provide the sulphur for amino acid biosynthesis, it is probably regulated. The regulatory controls of $\gamma-G T$ and the enzymes of the transsulphuration pathway are discussed in the light of current concepts of sulphur metabolism in S. cerevisiae.

\section{Methods}

Strains. Isogenic wild-type strains $\sum 1278 \mathrm{~b}(M A T \alpha)$ and 3962c (MATa) used in growth and genetic experiments were from this laboratory (Grenson et al., 1966). GSH-deficient (Gsh') yeast strains (Kistler et al., 1986) derived from the wild-type strain BK RBl were kindly provided by Dr Eckardt and colleagues. In order to eliminate auxotrophic mutations, the original isolate RB1/8 (MAT $\alpha$ Trp $^{-}$Ilv $^{-}$ $\left.\mathrm{Ade}^{-} \mathrm{Gsh}^{-}\right)$was crossed with strain 3962c. Sporulated diploids obtained after growth on acetate as a carbon source were dissected according to the classical procedure. $5 / 2$ tetrads showing a prototrophic character were obtained after selection on a minimal medium containing $\left(\mathrm{NH}_{4}\right)_{2} \mathrm{SO}_{4}$ and glucose as the sole sources of nitrogen and carbon respectively. A prototrophic spore progeny showing a clear $2: 2$ segregation for GSH deficiency was obtained by successive backcrossing of an otherwise prototrophic $\mathrm{Gsh}^{-}$segregant with strain $\sum$ 1278b. The enzymic defect was identified at the level of $\gamma$ glutamylcysteine synthetase (gsh $A$ ). Three segregants - gsh $A-1$, gsh $A-2$ and gsh $A-3$ - were chosen for the studies described below.

Growth conditions. Orbital shake batch cultures $(0.5$ and 1 litre) were inoculated from aerobic, stationary phase, glucose-grown precultures and incubated overnight at $29^{\circ} \mathrm{C}$ to obtain $S$. cerevisiae cells in the exponential growth phase. The cells were harvested at a maximum of $0.5-0.6 \mathrm{mg}$ dry wt $\mathrm{ml}^{-1}$ to obtain convenient samples for the determination of enzyme specific activities and metabolic intermediates. A minimal medium (MM) containing $50 \mathrm{mM}-\left(\mathrm{NH}_{4}\right)_{2} \mathrm{SO}_{4}$ and $3 \%(w / v)$ glucose as sole sources of nitrogen and carbon respectively was used as the standard medium (Messenguy, 1976). A solution containing $\mathrm{MgCl}_{2}(3 \mathrm{mM}), \mathrm{KH}_{2} \mathrm{PO}_{4}(7.5 \mathrm{mM}), \mathrm{CaCl}_{2}(3 \mathrm{mM}), \mathrm{NaCl}$ $(9 \mathrm{mM})$, citric acid $(50 \mathrm{mM})$ and $\mathrm{KOH}(160 \mathrm{mM})$ was used as a sulphurdeficient mineral medium for the experiments reported in Fig. 3. Numerous precautions were taken to avoid contamination with sulphur during the preparation of the medium. All glassware was acid cleaned and rinsed several times with double-deionized water (Milli-Q) before use. The chemicals were of reagent grade quality. The medium was prepared daily and dispensed into serum bottles to limit sulphide contamination from the ambient environment. The bottles were closed by butyl rubber stoppers, sealed with aluminium caps and then autoclaved. In the shifting experiments shown in Fig. 3, the cells were transferred under sterile conditions to the sulphur-deficient medium after rapid Millipore filtration (0.45 $\mu \mathrm{m}$ HAWP).

Enzyme assays. Cells were harvested at $4^{\circ} \mathrm{C}$ by centrifugation at $6000 \mathrm{~g}$ for $10 \mathrm{~min}$, washed twice with an appropriate buffer for the enzyme determination and resuspended in the same buffer. The cells were ruptured by passage through a French pressure cell. The homogenate was centrifuged $(27000 \mathrm{~g}$ for $15 \mathrm{~min})$ and the supernatant fluid was used as the enzyme source.

GSH synthetase (EC 6.3.2.3), $\gamma$-glutamyltranspeptidase (EC 2.3.2.2) and cysteinylglycine dipeptidase activities were assayed according to Jaspers $e t$ al. (1985). $\gamma$-Glutamylcysteine synthetase was assayed following Kistler et al. (1990). $\gamma$-Cystathionase (EC 4.4.1.1) was assayed by the following procedure (F. Ramos, personal communication): $0.5 \mathrm{ml}$ of enzyme solution (up to $1 \mathrm{mg}$ protein), previously filtered on Sephadex G-25, was incubated at $30^{\circ} \mathrm{C}$ for up to $5 \mathrm{~min}$ with $20 \mathrm{~mm}$-cystathionine $(0.1 \mathrm{ml})$ in the presence of potassium phosphate buffer $\mathrm{pH} 8.0(100 \mathrm{mM}, 0.4 \mathrm{ml})$ containing $50 \mu \mathrm{M}$-pyridoxal phosphate. The reaction was stopped by addition of $50 \mu 150 \%(w / v)$ trichloroacetic acid. After centrifugation for $5 \mathrm{~min}$ at $7000 \mathrm{~g}$, Lcysteine was estimated in $0.5 \mathrm{ml}$ supernatant by the procedure of Gaitonde (1967). Units of $\gamma$-cystathionase activity (U) are $\mu \mathrm{mols}$ of cysteine produced per hour. $O$-Acetyl-L-serine, the substrate for the assays of $O$-serine transsulphydrase (cysteine synthase; EC 4.2.99.8) was prepared according to Sheehan et al. (1956). Cysteine synthase was estimated by the following procedure: $0.3 \mathrm{ml}$ of enzyme solution (up to $1 \mathrm{mg}$ protein), previously filtered in Sephadex G-25, was incubated at $30{ }^{\circ} \mathrm{C}$ for up to $15 \mathrm{~min}$ with $10 \mathrm{mM}-\mathrm{Na}_{2} \mathrm{~S}(0.25 \mathrm{ml})$ and $100 \mathrm{~mm}-O$ acetyl-L-serine $(0.1 \mathrm{ml})$ in the presence of $\mathrm{Tris} / \mathrm{HCl}$ buffer $\mathrm{pH} 7.4$ (200 mM, $0.35 \mathrm{ml}$ ) containing $1 \mathrm{mM}-\mathrm{Na}_{2}$ EDTA. The reaction was stopped by addition of $50 \mu \mathrm{l} 50 \%(\mathrm{w} / \mathrm{v})$ trichloroacetic acid. After centrifugation for $5 \mathrm{~min}$ at $7000 \mathrm{~g}$, L-cysteine was estimated in $0.5 \mathrm{ml}$ supernatant by the procedure of Gaitonde (1967). Units (U) are $\mu$ mols of cysteine produced per hour.

All enzyme assay conditions ( $\mathrm{pH}$, temperature, substrate concentration, incubation time) were optimized in preliminary experiments not reported here.

Protein was estimated by the Lowry method.

Determination of metabolic intermediates. The method of Fahey et al. (1987) was adapted for the estimation of low-molecular-mass thiols in $S$. cerevisiae. Cells $\left( \pm 100 \mathrm{mg}\right.$ dry wt) were harvested at $4{ }^{\circ} \mathrm{C}$ by centrifugation at $6000 \mathrm{~g}$ for $5 \mathrm{~min}$, washed twice with HEPPS buffer (10 mM, pH 8.0), and flushed for $10 \mathrm{~min}$ with argon in septum-capped vial (serum tubes). Argon-satured aqueous $100 \mathrm{~mm}-\mathrm{HEPPS} / \mathrm{NaOH}$ $(0.5 \mathrm{ml}, \mathrm{pH} 8.0)$ containing $5 \mathrm{mM}$-EDTA and $2 \mathrm{~mm}$-monobromobimane (mBRB) was then added and the suspension, protected from light with aluminium foil, was allowed to stand for $5 \mathrm{~min}$ at $20^{\circ} \mathrm{C}$. Argonsaturated acetonitrile $(0.5 \mathrm{ml})$ was added and the sample was incubated for $15 \mathrm{~min}$ at $20^{\circ} \mathrm{C}$. The vial was opened and the cells were ruptured by sonication for $10 \mathrm{~min}$ with a Vibra Cell VC500 ultrasonic processor (Sonics Materials). Glacial acetic acid ( $1 \%, v / v$, final concentration) was added to the homogenate cooled in ice and the suspension was centrifuged at $27000 \mathrm{~g}$ for $15 \mathrm{~min}$. The supernatant was clarified on a Centriflo membrane (Amicon) for $10 \mathrm{~min}$ at $1500 \mathrm{~g}$ prior to HPLC analysis. For control samples, 2 mM-5,5'-dithiobis(2-nitrobenzoic acid) was substituted for mBRB during homogenization. Just after sonication, $\mathrm{mBRB}$ was added to a final concentration of $2 \mathrm{mM}$ and the mixture was allowed to react for $5 \mathrm{~min}$ at room temperature. Further processing of control samples was as described above. Analyses were done by HPLC (Waters) using a C18 Bondapak column according to Fahey \& Newton (1986).

A standard procedure (Ramos et al., 1970) was used fo the extraction of GSH and total amino acid pools in S. cerevisiae. Aliquots were passed through a Beckman $120 \mathrm{c}$ amino acid analyser. Reduced and oxidized glutathione (GSSG) were also estimated according to Eyer \& Podhradsky (1986) as indicated in the text.

\section{Results}

\section{Effect of GSH deficiency on metabolic intermediates of sulphur metabolism}

GSH was the major non-protein thiol in S. cerevisiae, even in the mutant strains where the total GSH content was only $7 \%$ of the wild-type value (Table 1 ). The other thiols were cysteine, $\gamma$-glutamylcysteine and $\mathrm{CoA}-\mathrm{SH}$. In 
Table 1. Effects of GSH deficiency on metabolic intermediates and enzymes involved in the general sulphur metabolism of $S$. cerevisiae

Cells of $S$. cerevisiae were harvested during the exponential growth phase. The values reported (means \pm SD; $n=3$ ) were determined as described in Methods.

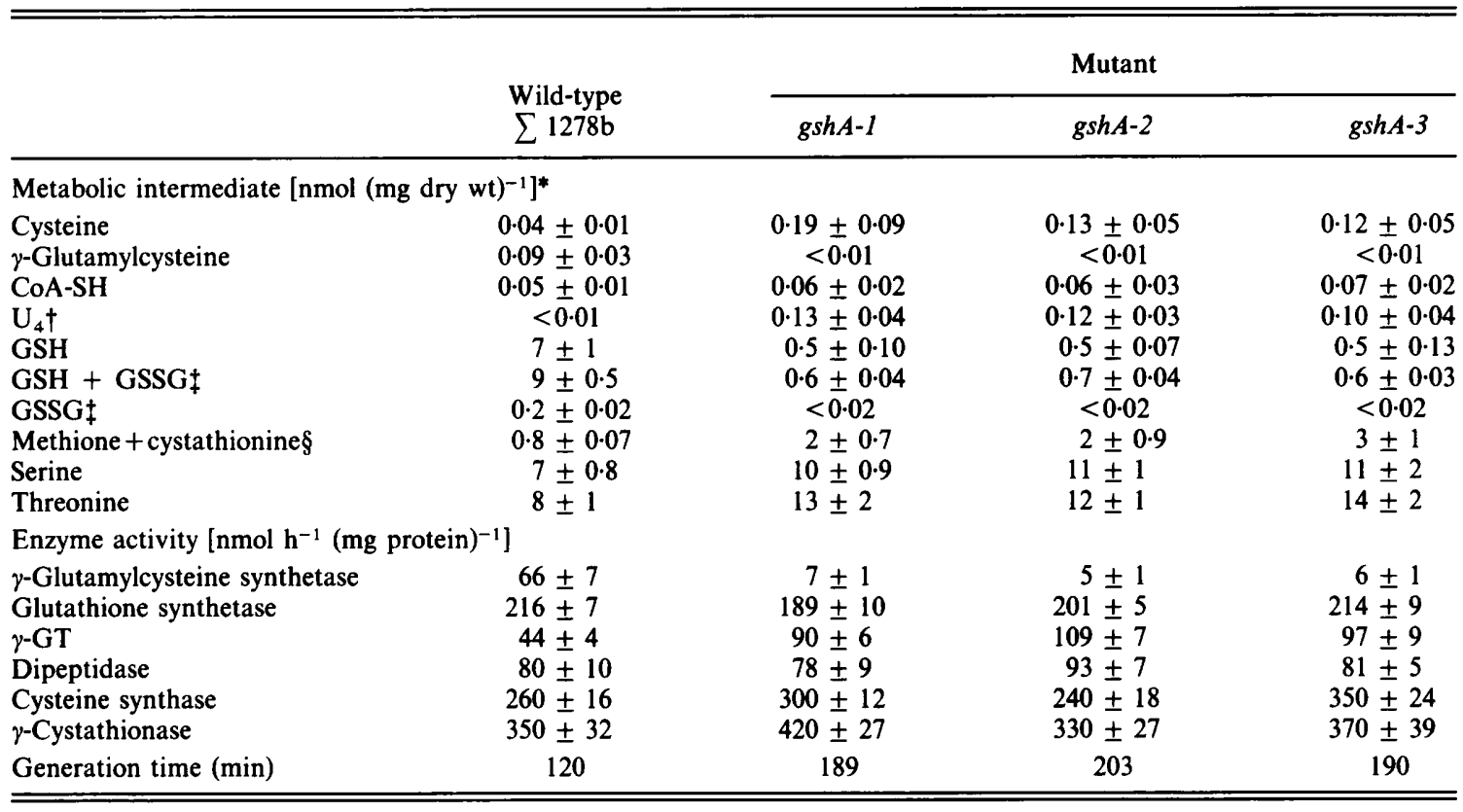

* Values for amino acids not affected by the mutation are not shown; a significant difference was, however, noted for ornithine and arginine.

$\dagger U_{4}$ denotes an unidentified thiol derivative having a retention time of $4 \mathrm{~min}$ in the tetrabutylammonium ion pairing system (Fahey \& Newton, 1986). The concentration was estimated using the fluorescence yield factor for the glutathione bimane derivative.

$\ddagger$ Reduced and oxidized glutathione were also measured according to Eyer \& Podhradsky (1986) as described in Methods.

$\S$ The assay technique used did not discriminate between methionine and cystathionine.

the GSH-deficient strains, however, the concentration of cysteine was about three times higher than in the wildtype and an unidentified thiol $\left(\mathrm{U}_{4}\right)$ was also detected. In contrast, $\gamma$-glutamylcysteine was not detected in the mutants. This is most probably due to the greatly lowered activity of $\gamma$-glutamylcysteine synthetase in the $\mathrm{Gsh}^{-}$ phenotype (Table 1). Some underestimation of the total thiol concentration measured by HPLC was likely since glutathione recovery was generally lower $( \pm 20 \%)$ than with the standard procedure (see Table 1 and Methods). This could be due to differences in extraction yields between the two protocols. Oxidized glutathione (GSSG) represented less than $2 \%$ of the GSH content in the wildtype strain and was not detected in the mutants. During the exponential growth phase the thiol:disulphide balance (GSH:GSSG) remained almost constant for strain $\sum 1278 \mathrm{~b}$, ranging between 50 and 60 . These values are similar to those obtained for other eukaryotic cells (Kosower \& Kosower, 1978). As previously shown, GSH deficiency leads to pleiotropic phenotypes of the mutants (Kistler et al., 1986). The lowered GSH levels in the haploid $\mathrm{Gsh}^{-}$mutants were related to an extension of the lag phase and a decrease in the growth rate when cells were cultivated on MM medium (Table 1).

Besides thiol compounds, the intracellular concentrations of certain amino acids were also affected by the mutation leading to GSH deficiency, especially when $S$. cerevisiae cells were grown on MM medium using ammonia as the nitrogen source (Table 1). Among the amino acids affected were threonine, serine, methionine or (and) cystathionine. Since all these are involved in the sulphur metabolism of $S$. cerevisiae, and since GSH represents more than $95 \%$ of the low-molecular-mass thiol pool in yeast, a link between GSH and general sulphur metabolism was considered. The sulphur atom of GSH could thus be transferred from cysteine to methionine via the $\gamma$-glutamyl cycle and the cystathionine pathway. The existence of a complete bidirectional transsulphuration pathway in yeast has been shown previously (Masselot \& de Robichon-Szulmajster 1975; Masselot \& Surdin-Kerjean, 1977).

Further investigations have emphasized a requirement for studies of enzyme regulation and GSH metabolism in order to support this assessment. 


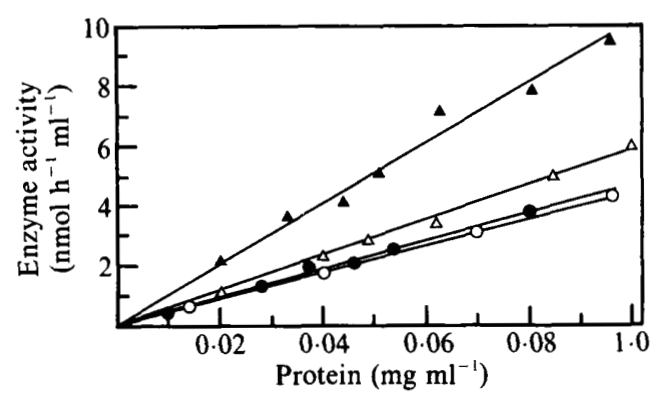

Fig. 1. Effect of GSH on the differential rate of $\gamma$-GT synthesis in a GSH-deficient strain of $S$. cerevisiae. Experimental procedures were as described in Methods. $\triangle, g \operatorname{sh} A-1 ; \triangle, g \operatorname{sh} A-1$ (+ $3 \mathrm{mM}-\mathrm{GSH}) ; 0, \Sigma$ $1278 \mathrm{~b} ; \mathrm{O}, \sum 1278 \mathrm{~b}(+3 \mathrm{~mm}-\mathrm{GSH})$.
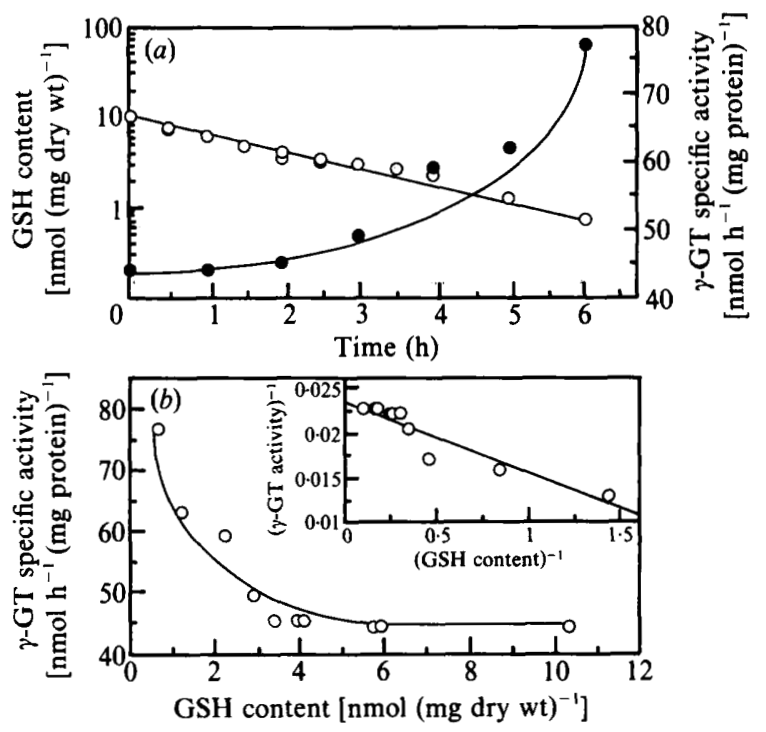

Fig. 2. (a) Effect of the addition of $1 \mathrm{mM}$-BSO (at zero time) on the intracellular pool of GSH $(O)$ and the specific activity of $\gamma$-GT $(O)$ in the wild-type strain $\sum 1278 \mathrm{~b}$. Experimental procedures were as described in Methods. (b) Relationship between $\gamma$-GT activity and cellular GSH content; inset, double reciprocal plot.

\section{Regulation of enzyme synthesis in relation to GSH deficiency}

As shown in Table 1, GSH deficiency has a noticeable influence on the specific activity of $\gamma$-GT. Indeed, in the $\mathrm{Gsh}^{-}$phenotype, the specific activity of $\gamma$-GT was about double that in the wild-type strain growing on the same medium. There was no apparent effect on cysteineglycine dipeptidase, the enzyme immediately downstream that catalyses the release of cysteine. In fact, it was previously observed (Jaspers et al., 1985) that this activity is shared by several peptidases constitutively produced by $S$. cerevisiae. The specific activities of the enzymes involved in cysteine biosynthesis, $\gamma$-cystathionase and cysteine synthase, were unaffected by the mutation leading to GSH deficiency (Table 1).
The effect of GSH on the differential rate of $\gamma$-GT synthesis was investigated. This thiol is apparently taken up unchanged by cells of $S$. cerevisiae (Jaspers et al., $1985)$ and does not affect the growth rate at concentrations up to at least $3 \mathrm{~mm}$. As shown in Fig. 1, addition of GSH to a culture of a deficient strain reduced the differential rate of $\gamma$-GT synthesis to a value close to that of the wild-type. The values [nmol $\left.\mathrm{h}^{-1}(\mathrm{mg} \text { protein })^{-1}\right]$ for the specific activities were as follows: $g \operatorname{sh} A-1,99 \pm 5$; gsh $A-1$ ( + GSH), $60 \pm 2 ; \sum 1278 \mathrm{~b}, 47 \pm 2 ; \sum 1278 \mathrm{~b}$ $(+\mathrm{GSH}), 44 \pm 2$.

Buthionine-( $S, R)$-sulphoximine (BSO), a specific transition-state inhibitor of $\gamma$-glutamylcysteine synthetase (Griffith \& Meister, 1979), lowered the GSH level in cells of $S$. cerevisiae (Fig. 2). Depletion with BSO enabled us to check the effect of GSH on $\gamma$-GT biosynthesis in the wild-type strain $\sum 1278 \mathrm{~b}$. The growth rate of the strain was apparently unaffected by the analogue at a concentration of $1 \mathrm{mM}$, but the specific activity of $\gamma-\mathrm{GT}$ increased progressively while the intracellular GSH pool declined (Fig. 2a). The rate of GSH disappearance was used as a measure of GSH utilization. The log-linear regression applied to the data yielded a half-life time $\left(t_{1 / 2}\right)$ of $105 \pm 4 \min (r=0.990, n=16)$, which was close to the rate of dilution due to growth (see Fig. $2 a$ and Table 1). This is not surprising, since the turnover rate of glutathione during growth on MM medium is exceedingly slow ( $t_{1 / 2}$ about $900 \mathrm{~min}$; see Jaspers et al., 1985). Fig. $2(b)$ shows the relationship between the level of $\gamma$-GT activity and the internal GSH content. Since a linear dependence is observed in a double reciprocal plot, it is possible that regulation of $\gamma$-GT could display an element of saturation kinetics, but this problem requires further investigation. For concentrations of GSH higher than $4 \mathrm{nmol}(\mathrm{mg} \text { dry } \mathrm{wt})^{-1}$ there were no apparent effects on the level of the enzyme. This could explain why the differential rate of $\gamma$-GT synthesis was unaffected in a wild-type strain growing on medium supplemented with GSH (Fig. 1). It seems, therefore, that the enzyme derepression observed in $g s h A$ mutants is unlikely to result from a mutation in regulatory genes, but rather is due to an alteration of the thiol status.

\section{GSH pool changes}

The role of GSH as an endogenous sulphur source for $S$. cerevisiae is shown in Fig. 3. Cells preincubated in MM medium containing sulphate as a sulphur source were transferred into a fresh medium devoid of any sulphur nutrient. Under the experimental conditions of Fig. 3(a), the wild-type strain $\sum 1278 \mathrm{~b}$ continued to grow for $2 \mathrm{~h}$ before reaching stationary phase (not shown). During this time the GSH pool decreased to about $10 \%$ of its normal value and methionine + cystathionine remained 
Glutathione metabolism in Saccharomyces cerevisiae

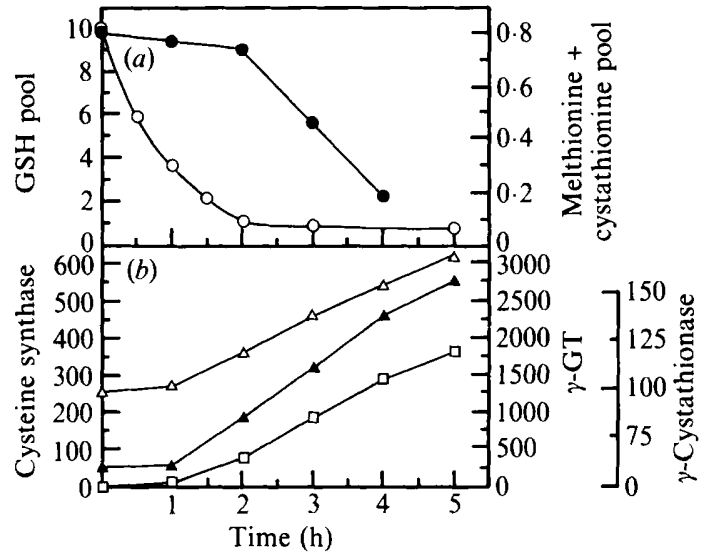

Fig. 3. Effect of sulphate deprivation on (a) pools of sulphur amino acids [ $\mathrm{nmol}(\mathrm{mg} \text { dry wt })^{-1}$ ] and $(b)$ specific activities of enzymes [nmol $\left.\mathrm{h}^{-1}(\mathrm{mg} \text { protein })^{-1}\right]$ in the wild-type strain $\sum 1278 \mathrm{~b}$. At zero time, the cells were transferred into a sulphate-deficient medium as described in Methods. O, GSH; O, methionine + cystathionine; $\square, \gamma$-GT; $\mathbf{\Delta}, \gamma$ cystathionase; $\triangle$, cysteine synthase.

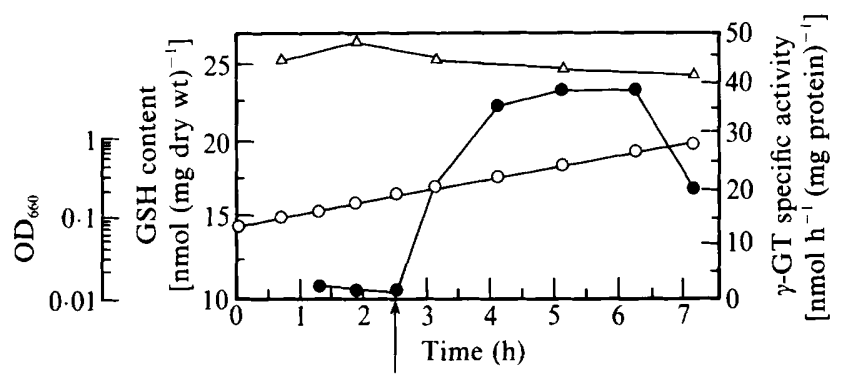

Fig. 4. Effect of exogenous L-methionine $\left(1 \mathrm{mg} \mathrm{m}^{-1}\right)$ on the internal pool of GSH in the wild-type strain $\sum 1278 \mathrm{~b}$. Experimental procedures were as described in Methods; the time of methionine addition is indicated by an arrow. $O$, Growth curve (optical density at $660 \mathrm{~nm}$ ); , GSH pool; $\triangle, \gamma$-GT activity.

unaffected (Fig. 3a). After the GSH depletion phase, a net decrease in the concentration of the sulphur compounds was observed. Moreover, $\gamma$-GT, cysteine synthase and $\gamma$-cystathionase were derepressed when the intracellular concentration of GSH fell below $4 \mathrm{nmol}(\mathrm{mg}$ dry $w t)^{-1}$ (Fig. $4 b$ ). The rate of glutathione disappearance was calculated for the first $2 \mathrm{~h}$ after the shifting experiment shown in Fig. 3 : the $t_{1 / 2}$ value was $38 \pm 1$ $\min (r=0.998, n=4)$.

Additional evidence that GSH functions as a storage form of reduced sulphur was obtained from studies with L-methionine. Incubation of wild-type cells with Lmethionine induced a transitory stimulation of GSH biosynthesis (Fig. 4). A very slight effect was observed for GSH in the mutant strains (not illustrated). Previous studies have shown that methionine is taken up by $S$. cerevisiae cells but cannot serve as a nitrogen source (Gits \& Grenson, 1967). Methionine in excess is rapidly converted into $S$-adenosyl-L-methionine which is accumulated in yeast vacuoles (Schlenk \& DePalma, 1957; Nakamura \& Schlenk, 1974). The experiment reported above suggests that the sulphur atoms of methionine could be incorporated into GSH via the cystathionine pathway and the $\gamma$-glutamyl cycle. The intracellular concentration of GSH reflects the equilibrium between synthesis and degradation, the latter catalysed mainly by $\gamma$-GT. Since the level of $\gamma$-GT activity was unaffected by methionine under the experimental conditions illustrated in Fig. 4, the transitory nature of GSH accumulation could be explained by a slow response of one or several enzyme(s) to regulatory signals, because the $\gamma$-glutamylcysteine synthetase reaction is the rate limiting step in GSH biosynthesis and is feedback inhibited by GSH under conditions similar to those that prevail in vivo (see in Meister \& Anderson, 1983).

\section{Discussion}

A working model for the main fluxes of sulphur in $S$. cerevisiae is shown in Fig. 5. This model links data published on sulphur metabolism in $S$. cerevisiae (Jones \& Fink, 1982; Ono et al., 1988) with our results on GSH metabolism. Potentially, two pathways exist for the synthesis of cysteine. The first (reactions 1 and 2) proceeds by acetylation of serine to yield $O$-acetylserine, followed by a sulphydrylation. The latter step can be catalysed by at least two cysteine synthase isoenzymes (Yamagata, 1980). The second pathway proceeds from homocysteine and involves the cystathionine biosynthesis cycle (reactions 5 to 8; Masselot \& de RobichonSzulmajster, 1975; Masselot \& Surdin-Kerjean, 1977). The final release of cysteine is catalysed by $\gamma$-cystathionase. It is also assumed that the $\gamma$-glutamyl cycle (reactions 14 to 17) can function to meet the intracellular requirement for cysteine, and is thus involved in the overall regulation of sulphur metabolism. The suppression of this regulating effect in the $\mathrm{Gsh}^{-}$haploids could provide a plausible explanation for the high level of the transsulphuration intermediates (Table 1). In the presence of sulphate as a nutrient, most of the excess sulphur is incorporated into glutathione. Under these conditions, $\gamma$-GT activity is low and the turnover rate of GSH is exceedingly slow (Fig. 2 and Jaspers $e t$ al., 1985). When cells are deprived of sulphate, GSH is apparently able to serve as an internal sulphur source until it reaches a residual concentration of about $10 \%$ of its normal value. An increase in the specific activity of $\gamma$-GT is attained by derepressing synthesis of the enzyme and, as a consequence, the turnover rate of GSH increases (Fig. 3). The model requires that derepression of the bidirectional transsulphuration pathway (reactions 5 to 8 in Fig. 5) 


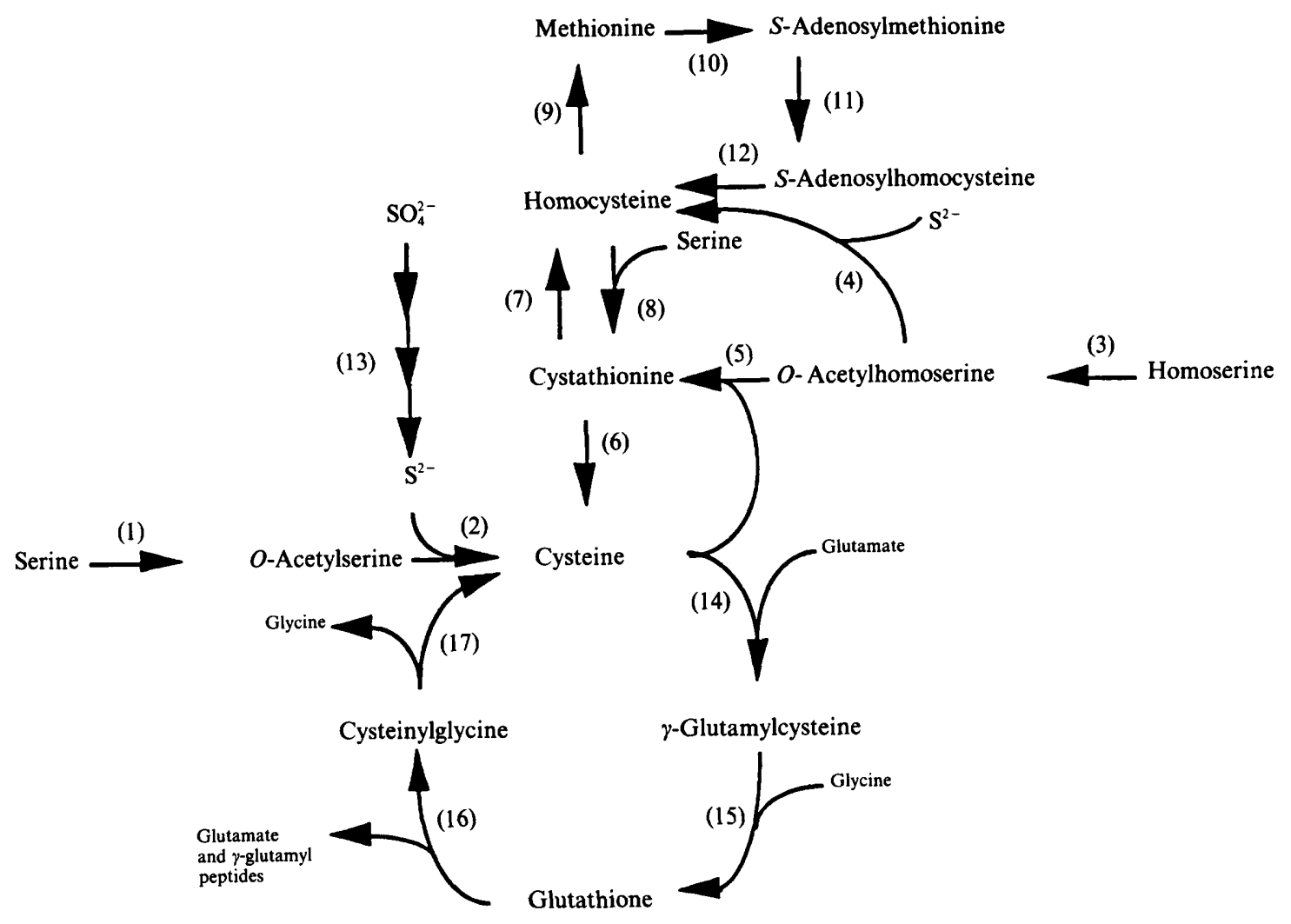

Fig. 5. A model for the main fluxes of sulphur in S. cerevisiae. (1) Serine acetyltransferase; (2) cysteine synthase; (3) homoserine acetyltransferase; (4) homocysteine synthase; (5) $\gamma$-cystathionine synthase; (6) $\gamma$-cystathionase; (7) $\beta$-cystathionase; (8) $\beta$-cystathionine synthase; (9) homocysteine methyltransferase; (10) $S$-adenosylmethionine synthetase; (11) $S$-adenosylmethionine demethylase; (12) adenosylhomocysteinase; (13) sulphate-reducing pathway; (14) $\gamma$-glutamylcysteine synthetase; (15) GSH synthetase; (16) $\gamma$-GT; (17) cysteinylglycine dipeptidase.

leads to a more active transfer of the sulphur atom from cysteine to methionine and vice versa. Pasewski et al. (1984) suggested that GSH, in addition to cysteine, could act as an effector regulating the biosynthesis of the enzymes of sulphur metabolism in the fungus Aspergillus nidulans. Here we have found that in $S$. cerevisiae, the effectors governing the biosynthesis of the transsulphuration enzymes are apparently different from those playing a role in $\gamma$-GT regulation, since $\gamma$-cystathionase and cysteine synthase remain unaffected by the GSH deficiency in gshA mutants. Derepression of $\gamma$-GT correlates best with a decrease in the GSH pool among the sulphur compounds examined (Table 1 and Fig. 2). This is not the case for $\gamma$-cystathionase and cysteine synthase. The two regulatory circuits appear to be distinct and it is only in conditions of total sulphate deprivation that all these enzymes are derepressed.

Interestingly, only $90 \%$ of the GSH pool is mobilizable to serve as an endogenous sulphur source. From experiments with BSO, approximately $10 \%$ of the wild- type GSH content is the minimum critical level (Fig. 2). Cells containing about $1 \mathrm{nmol}$ GSH (mg dry wt) ${ }^{-1}$ or more are apparently able to grow normally; we do not know if a complete lack of GSH is lethal in S. cerevisiae since the growth rate decreases dramatically below this value. Kistler et al. (1986) reported that a residual GSH level of $1 \%$ of the wild-type value, as found in GSHdeficient mutants ( $g s h A$ ), leads to serious impairments of the plating efficiencies of the cells and their respiration ability accompanied by a loss of mitochondrial DNA. Some eukaryotic cells have a GSH mitochondrial pool which is stable and physiologically distinct from the cytoplasmic pool (Meredith \& Reed, 1982). During severe drug intoxication, extensive depletion of the cytoplasmic GSH pool had less damaging consequences than depletion of the mitochondrial pool (Reed et al., 1983). Such compartmentation, however, remains to be demonstrated for $S$. cerevisiae.

In summary, our data strongly support a previously undemonstrated role for GSH in $S$. cerevisiae. GSH 
Glutathione metabolism in Saccharomyces cerevisiae

might have a storage function, similar to glycogen, trehalose, polyphosphate or lipids (Gancedo \& Serrano, 1989). In $S$. cerevisiae $\gamma$-GT is a vacuolar enzyme and, in the strain investigated, about $50 \%$ of the total cellular GSH is concentrated in the central vacuole (Jaspers \& Penninckx, 1984). It is suggested, therefore, that GSH fulfils the role of a storage compound which can be mobilized during starvation and/or reproduction. Substantial portions of the intracellular amino acids are compartmentalized within the cell, mainly in the vacuole. Redistribution of amino acids between compartments in response to metabolic signals has been demonstrated (Wiemken, 1980; Messenguy et al., 1980; Kitamoto et al., 1988). However, to what extent compartmentalization of metabolites may play a role in regulation of pathways other than in amino acid biosynthesis is as yet unknown and further research work along these lines is in progress.

M.T.E. was the recipient of a fellowship from the Institut pour l'Encouragement de la Recherche Scientifique dans l'Industrie et l'Agriculture (IRSIA). This work was supported in part by research grants from the Fonds National de la Recherche Scientifique (FNRS) to M.J.P. and an Action de Recherche Concertée (ARC) financed by the Belgian State.

We wish to thank Dr F. Eckardt for the gift of Gsh- strains, Mr F. Ramos for communicating the $\gamma$-cystathionase measurement protocol and $\mathrm{Dr} J$. Bechet for helpful discussions. The skilful assistance of Miss M. Demoulin, Mr D. Gigot and Mr J. P. Ten Have was very much appreciated.

\section{References}

Cheng, H., Aronson, A. \& Holt, S. (1973). Role of glutathione in the morphogenesis of the bacterial spore coat. Journal of Bacteriology 113, $1135-1143$.

Elskens, M., Penninckx, M., Vandeloise, R. \& Vander Donckt, E. (1988). Use of a Simplex technique and contour diagrams for the determination of the reaction rate constants between glutathione and Thiram in the presence of NADPH. International Journal of Chemical Kinetics 20, 837-848.

EYER, P. \& PODHRADSKY, D. (1986). Evaluation of the micromethod for determination of glutathione using enzymic cycling and Ellman's reagent. Analytical Biochemistry 153, 57-66.

FAHEY, R. \& NEWTON, G. (1986). Determination of low molecular weight thiols using monobromobimane fluorescent labeling and high-performance liquid chromatography. Methods in Enzymology $143,85-96$.

FAHEY, R., BuschBaChER, R. \& NEWton, G. (1987). The evolution of glutathione in phototrophic microorganisms. Journal of Molecular Evolution 25, 81-88.

GAITONDE, M. K. (1967). A spectrophotometric method for the direct determination of cysteine in the presence of other naturally occurring amino acids. Biochemical Journal 104, 627-633.

GaNCEDO, C. \& SERRANo, R. (1989). Energy yielding metabolism. In The Yeasts, 2nd edn, vol. 3, p. 205. Edited by A. H. Rose \& J. S. Harrison. London: Academic Press.

Giddings, T., Wolk, P. \& Shomer-Ilan, A. (1981). Metabolism of sulphur compounds by whole filaments and heterocysts of Anabaena variabilis. Journal of Bacteriology 146, 1067-1074.

GiTs, J. \& Grenson, M. (1967). Multiplicity of the amino acid permeases in Saccharomyces cerevisiae. III. Evidence for a specific methionine-transporting system. Biochimica et Biophysica Acta 135, 507-516.

Grenson, M., Mousset, M., Wiame, J. M. \& Béchet, J. (1966). Multiplicity of the amino acid permeases in Saccharomyces cerevisiae. I. Evidence for a specific arginine-transporting system. Biochimica et Biophysica Acta 127, 325-338.

Griffith, O. W. \& MeISTER, A. (1979). Potent and specific inhibition of glutathione synthesis by buthionine sulfoximine ( $S$-n-butyl homocysteine sulfoximine). Journal of Biological Chemistry 254, 7558-7560.

JASPERS, C. \& PENNINCKX, M. (1981). On the role of glutathione in the transport of amino acid in the yeast Saccharomyces cerevisiae: contradictory results. FEBS Letters 132, 41-43.

J ASPERS, C. \& PENNINCKX, M. (1984). Glutathione metabolism in the yeast Saccharomyces cerevisiae. Evidence that $\gamma$-glutamyltranspeptidase is a vacuolar enzyme. Biochimie 66, 71-74.

Jaspers, C., Gigot, D. \& Penninckx, M. (1985). Pathways of glutathione degradation in the yeast Saccharomyces cerevisiae. Phytochemistry 24, 703-707.

JoNEs, E. W. \& FINK, G. R. (1982). Amino acid and nucleotide biosynthesis. In The Molecular Biology of the Yeast Saccharomyces cerevisiae: Metabolism and Gene Expression, pp. 181-299. Edited by J. N. Strathen, E. W. Jones \& J. R. Broach. Cold Spring Harbor, NY: Cold Spring Harbor Laboratory.

KistLer, M., SUmmer, K. H. \& ECKARdT, F. (1986). Isolation of glutathione-deficient mutants of the yeast Saccharomyces cerevisiae. Mutation Research 173, 117-120.

Kistler, M., MaIER, K. \& ECKARDT, F. (1990). Genetic and biochemical analysis of glutathione-deficient mutants of Saccharomyces cerevisiae. Mutagenesis 5, 39-44.

Kitamoto, K., Yoshizawa, K., Ohsumi, Y. \& ANRaku, Y. (I988). Dynamic aspects of vacuolar and cytosolic amino acid pools of Saccharomyces cerevisiae. Journal of Bacteriology 170, 2683-2686.

Kosower, N. S. \& Kosower, E. M. (1978). The glutathione status of cells. International Review of Cytology 54, 109-160.

MASSELOT, M. \& DE ROBiCHON-SZulmajster, H. (1975). Methionine biosynthesis in Saccharomyces cerevisiae. I. Genetic analysis of axotrophic mutants. Molecular and General Genetics 139, 121-132.

Masselot, M. \& SURdin-KerJan, Y. (1977). Methionine biosynthesis in Saccharomyces cerevisiae. II. Gene-enzyme relationships in the sulphate assimilation pathway. Molecular and General Genetics 154, 23-30.

MEISTER, A. (1983). Metabolism and transport of glutathione and other $\gamma$-glutamyl compounds. In Functions of Glutathione: Biochemical, Physiological, Toxicological and Clinical Aspects, pp. 39-49. Edited by A. Larsson, S. Orrenius, A. Holmgren \& B. Mannervik. New York: Raven Press.

Meister, A. \& ANDerson, M. E. (1983). Glutathione. Annual Review of Biochemistry 52, 711-760.

MEREDITH, M. J. \& REED, D. J. (1982). Status of the mitochondrial pool of glutathione in the isolated hepatocyte. Journal of Biological Chemistry 116, 13-16.

MessenguY, F. (1976). Regulation of arginine biosynthesis in Saccharomyces cerevisiae: Isolation of a cis-dominant constitutive mutant for ornithine carbamoyl transferase. Journal of Bacteriology $128,49-55$.

Messenguy, F., Colin, D. \& Ten Have, J. P. (1980). Regulation of compartmentation of amino acid pools in Saccharomyces cerevisiae and its effects on metabolic control. European Journal of Biochemistry 108, 439-447.

Nakamura, K. D. \& Schlenk, F. (1974). Active transport of exogenous $S$-adenosylmethionine and related compounds into cells and vacuoles of Saccharomyces cerevisiae. Journal of Bacteriology 120 , 482-487.

Ono, B. I., Shirage, Y. I., Nanjoh, A., Andou, N., Ohue, H. \& ISHINO-ARAO, Y. (1988). Cysteine biosynthesis in Saccharomyces cerevisiae: mutation that confers cystathionine $\beta$-synthase deficiency. Journal of Bacteriology 170, 5883-5889.

Paszewski, A., Prazmo, W., Nadolska, J. \& Regulski, M. (1984). Mutations affecting the sulphur assimilation pathway in Aspergillus nidulans: their effect on sulphur amino acid metabolism. Journal of General Microbiology 130, 1113-1121. 
Payne, G. M. \& PAYNe, J. W. (1984). $\gamma$-Glutamyltransferase is not involved in the bulk uptake of amino acids, peptides or $\gamma$-glutamylamino acids in yeast (Saccharomyces cerevisiae). Biochemical Journal 218, 147-155.

Penninckx, M. \& Jaspers, C. (1982). On the role of glutathione in microorganisms. Bulletin de l'Institut Pasteur 80, 291-301.

Penninckx, M., Jaspers, C. \& Legrain, M. (1983). The glutathionedependent glyoxalase pathway in the yeast Saccharomyces cerevisiae. Journal of Biological Chemistry 258, 6030-6036.

Ramos, F., ThuriauX, P., Wiame, J. M. \& Bechet, J. (1970). The participation of ornithine and citrulline in the regulation of arginine metabolism in Saccharomyces cerevisiae. European Journal of Biochemistry 12. 40-47.

Reed, D. J., Brodie, A. E. \& Meredith, M. J. (1983). Cellular heterogeneity in the status and functions of cysteine and glutathione. In Functions of Glutathione: Biochemical, Physiological, Toxicological and Clinical Aspects, pp. 39-49. Edited by A. Larsson, S. Orrenius, A. Holmgren \& B. Mannevik. New York: Raven Press.
RENNENBERG, H. (1982). Role of glutathione in plant cells. Phytochemistry 21, 2771-2775.

RoBINS, R. \& DAviEs, D. (1981). Lack of correlation between GSH turnover and amino acid absorption by the yeast Saccharomyces cerevisiae. Phytochemistry 20, 1497-1499.

Schlenk, F. \& Depalma, R. E. (1957). The formation of $S$ adenosylmethionine in yeast. Journal of Biological Chemistry 229, 1037-1050.

Sheehan, J. C., Goodman, M. \& Hess, G. P. (1956). Peptide derivatives containing hydroxyaminoacids. Journal of the American Society 78, 1367-1369.

WIEMKeN, A. (1980). Compartmentation and control of amino acid utilization in yeasts. In Cell Compartmentation and Metabolic Channeling, p. 225. Amsterdam: Elsevier/North Holland Biomedical Press.

YamaGaTA, S. (1980). Occurrence of low molecular weight $O$ acetylserine sulfhydrylase in the yeast Saccharomyces cerevisiae. Journal of Biochemistry 88, 1419-1427. 